\title{
Measuring body condition of lizards: a comparison between non-invasive dual-energy $X$-ray absorptiometry, chemical fat extraction and calculated indices
}

\section{Guy Sion ( $\sim$ guy.sion@gmail.com )}

Tel Aviv University Department of Zoology

Maggie J. Watson

Charles Sturt University https://orcid.org/0000-0001-6021-9686

Amos Bouskila

Ben-Gurion University of the Negev

\section{Research}

Keywords: three to ten

Posted Date: July 27th, 2020

DOI: https://doi.org/10.21203/rs.3.rs-47832/v1

License: (c) (i) This work is licensed under a Creative Commons Attribution 4.0 International License.

Read Full License

Version of Record: A version of this preprint was published at Frontiers in Zoology on January 5th, 2021. See the published version at https://doi.org/10.1186/s12983-020-00382-w. 


\section{Abstract \\ Background}

Condition indices (Cls) are used in ecological studies as a way of measuring an individual animal's health and fitness. Noninvasive Cls are estimations of a relative score of fat content or rely on a ratio of body mass compared to some measure of size, usually a linear dimension such as tarsus or snout-vent length. Cls are generally measured invasively by lethal fat extraction as in a seasonal sample of individuals in a population. Many alternatives to lethal fat extraction are costly or time consuming. As an alternative, dual-energy X-ray absorptiometry (DXA) allows for non-destructive analysis of body composition and enables multiple measurements during an animal's life time. DXA has never been used for ecological studies in a small, free-ranging lizard before, therefore we calibrated this method against a chemical extraction of fat from a sample of 6 geckos (Israeli fan toed gecko Ptyodactylus guttatus) ranging in body mass between $4.2-11.5 \mathrm{~g}$.

\section{Results}

We found that fat mass measured with DXA was significantly correlated with the mass of chemically extracted fat for specimens more than $4.8 \mathrm{~g}\left(N=5, R^{2}=0.995, P<0.001\right)$. Fat percentage regressed with body mass significantly predicted the DXA fat percentage $\left(N=30, R^{2}\right.$ adj. $\left.=0.875, P<0.001\right)$. Live wet mass was significantly correlated with calculated fat mass $\left(N=30, R^{2}=0.984, P<0.001\right)$ for specimens more than $4.8 \mathrm{~g}$. Among the other calculated non-invasive Cls that we tested, the best was mass/SVL (provide $\mathrm{N}$, correlation coeff and $\mathrm{p}$ value).

\section{Conclusions}

We recommend that in situations where DXA cannot be used, that the most accurate of the body condition estimators for both males and females in this species is mass/SVL (snout-vent length) for both sexes.

\section{Background}

Many animal ecology studies rely on methods to determine the body condition of different individuals in a population (Stevenson \& Woods 2006). Both destructive (body composition) and non-destructive (body mass and linear measures of body size) are used to estimate or determine the condition index (Cl) of an individual. Body condition is assumed to influence an animal's health and fitness and may affect many aspects in an organism's life such as social status (dark-bellied brent geese Branta bernicla bernicla, Poisbleau, 2006), reproductive success (Crimson Finch Neochmia phaeton, Milenkaya et al. 2015), foraging strategy (White-tailed Deer Odocoileus virginianus, Taillon, \& Côté, 2007; Meerkat Suricata suricatta, Thornton, 2008), survival through stressed periods (Golden-mantled Ground Squirrels 
Callospermophilus lateralis, Wells et al. 2019), disease status (green sea turtle Chelonia mydas, Rossi et al. 2019) and dispersal (Viviparous Lizard Zootoca vivipara, Meylan et al. 2002). It is highly desirable to understand body condition, both temporally and ontogenetically in order to provide supporting evidence and mechanistic linkages for population studies (Stevenson \& Woods 2006). In population studies of species of conservation importance, new and improved non-destructive methods for body condition indices are increasingly important (Speakman 2001, Peig \& Green 2009).

Body fat, due to its high energy content, is a good estimator of body condition of an animal (Hadley, 1985). Body fat reserves directly influence fitness and are highly dependent on season, reproductive status and periods of fasting (e.g., Atkinson \& Ramsay 1995, Stephenson et al. 2002). The most accurate measure of body fat is the direct approach wherein several individual animals are euthanized and have the fat extracted chemically from the carcasses (e.g., Xuefeng \& Yilian 2003, Prestrud \& Pond 2003). This destructive approach is, however, complicated, time consuming and does not allow for comparisons of body composition within and between seasons on the same individuals. Non-destructive techniques include various body condition indices (ratio of body mass to a linear dimension of body size, or the residuals of the regression between body mass and size; Green 2001; Secor \& Nagy, 2003), isotope dilution (Servello, et al. 2005), bioelectrical impedance analysis (BIA, Hwang et al. 2005), total body electrical conductivity (TOBEC, Angilletta 1999, Scott et al. 2001), lipid-soluble gas absorption (Henen, 2001), quantitative magnetic resonance (QMR) (Riley et al. 2016), and dual-energy X-ray absorptiometry (DXA) (Nagy 2001).

Bioelectrical Impedance Analysis (BIA) appears to be a better predictor of energy stores than body condition estimates calculated from mass and SVL (Wirsing et al. 2002). However, the repeatability and accuracy are not sufficient to monitor small changes in Lean Body Mass (LBM) and lipid stores (Secor and Nagy, 2003). Among the alternative techniques, DXA, holds the most promise as an easy and accurate measure, especially for smaller animals. DXA scans the body with two X-ray beams of different energy levels and uses the attenuation of the energy of those two X-ray beams to determine the tissue signature and to quantify total body mass, lean mass and fat mass of the organism (Korine et al. 2004).

DXA has been used to assess nutritional status in captive rhesus monkeys Macaca mulatta (compared with stable isotope dilution, no validation, Blanc et al. 2005); determine bone density distribution patterns in museum skulls of delphinids and beaked whales (Cozzi et al. 2010); measure fat mass in small migratory birds (validated with freeze-dried carcasses, Korine et al. 2004), identify metabolic bone disease and bone mineral density in captive green iguanas Iguana iguana (no validation, Zotti et al. 2004), determine the body composition of diamondback water snakes Nerodia rhombifer (validated with euthanized individuals, Secor \& Nagy, 2003) and channel catfish Ictalurus punctatus (validated with euthanized individuals, Johnson et al. 2017). In reptiles, body condition is generally determined by morphometric measurements (Hayes \& Shonkwiler 2001, Stevenson \& Woods 2006) which are rarely tested against other Cls or validated (but see Secor \& Nagy, 2003, Falk et al. 2017). The use of DXA has not been tested for its applicability for studies of small lizards, thus our primary objective is to assess the use of DXA as a practical method for determining body fat composition, and therefore use as a $\mathrm{Cl}$, in a 
small lizard. Our specific goals are (1) to evaluate the accuracy of DXA in predicting body fat composition of a small lizard by comparing DXA to chemically extracted fat, (2) to compare the accuracy of this method for males, females and juveniles, and (3) to quantify the relationship between five common estimators of body condition (based on mass and/or length relationships) with body fat determined from DXA.

\section{Methods}

\section{Study site and organism}

The study was conducted at Midreshet Ben-Gurion in the northern Negev desert, Israel $\left(30^{\circ} 51^{\prime} 8.27^{\prime \prime} \mathrm{N}\right.$ $34^{\circ} 47^{\prime} 0.24^{\prime \prime} \mathrm{E}$ ) from summer 2003 until autumn 2004. The study site was a complex of guest rooms surrounded by a two-meter high wall over an area $13 \times 150 \mathrm{~m}$. A dense population of the Israeli fan-toed gecko Ptyodactylus guttatus inhabited the premises (Sion, 2006; 2015; 2018). The Israeli fan-toed gecko is a medium-sized, insectivorous, rupiculous, scansorial lizard (Frankenberg, 1978; Werner, 1972) in the family Phyllodactylidae (Gamble et al. 2008) common in mesic and arid parts of the Middle East (Israel, Egypt, Saudi Arabia, Oman, Palestine, Jordan, and Syria). It often inhabits cliffs or masonry walls where it can easily be observed from a distance (Werner, 1965, 1986, 2016; Frankenberg, 1978; Werner \& Sivan, 1994; Sion, 2006; 2015, 2018; Johnston \& Bouskila, 2007).

Fifty-five geckos were hand captured, measured (morphometrics) and scanned (DXA) and released at the site of capture. Of these, 30 gecko's scan data were included in the comparison, since their body mass was above the lowest possible accurate reading with minimal body mass $(>4.8 \mathrm{~g})$ as indicated in the results (Table 1). The snout vent length (SVL) of these 30 geckos was $60.6-91.7 \mathrm{~mm}$ and their body mass $4.99-22.5 \mathrm{~g}$. We used these 30 geckos to compare the real wet mass (as measured by a scale) and the wet mass measure by DXA (see below). From each captured gecko, we recorded the mass using Ohaus digital scale to $0.1 \mathrm{~g}$ precision, snout-vent length (SVL), using digital calipers, and the width at the base of the tail. Six additional individuals were captured and euthanized for the calibration necessary for this study (two males, three females and one too small to be sexed without a probe). The snout vent length (SVL) of these geckos was 61.5-91.7 mm and their body mass 4.8-11.5 g (The smallest gecko 55.6 $\mathrm{mm}$ with body mass $4.2 \mathrm{~g}$ was excluded to improve accuracy from $55 \%$ to $8.5 \%$ error). We killed only six geckos in order to minimize destructive sampling as much as possible.

\section{Dual-energy X-ray Absorptiometry (DXA) measurements}

Geckos were anesthetized using cotton balls wet with Isofluran which was inserted with the gecko in a sealed jar for a minute or less until the gecko stopped moving. Each gecko was scanned twice using a Lunar PIXImus ${ }^{\circledR} 2$ densitometer (software version 1.46, originally manufactured for scanning rodents, e.g., Nagy \& Clair 2000). Each scan takes approximately $5 \mathrm{~min}$, and requires that the animal remains immobile for the duration of the scan (Secor \& Nagy, 2003). For each lizard we averaged the values we measured in the two scans. Scans were analyzed using the manufacturer's software that provided a measure of fat mass, fat percentage and lean mass. Theses 30 scan results were also used to compare 
the measured (calibrated) body fat percentage with the different indices for body condition. Immediately after DXA analysis, the six individuals chosen for chemical analysis were killed with an overdose of Isofluran and frozen at $-20^{\circ} \mathrm{C}$ until analyzed for carcass composition.

\section{Chemical analysis}

The DXA protocol designates the machine for 10-50 g. mice. But it has been used for other species such as bats and birds to measure fat content and body composition. We decided to examine the performance of the machine for smaller size animals to find the lower limit of the machine's detection abilities. The six euthanized geckos were kept frozen and then were freeze-dried until constant mass was achieved ( 2 days). The dried body was then ground and extracted with petroleum ether in a Soxhlet apparatus to determine fat mass using the methods of Dobush et al. (1985) with guidance from Noga Kronfeld-Schor (following Gutman et al. 2005). In short, a small sample was taken from each ground carcass, inserted into a (tared) empty tea bag and weighed on analytical scales (empty bags supplied by Lipton ${ }^{\mathrm{TM}}$ ). Each sample was weighed $\pm 0.0001 \mathrm{~g}$. on an analytical balance (Ohaous), in the tea bag before fat was washed out by the organic solvent petroleum ether. The fat was washed out during repetitive washes, using a set of glass tubes that enable the solvent that washed fat into a glass jar, to evaporate by heat and liquidize over the samples. The solvent was recycled for repetitive washes for two days.

\section{Data analysis}

We used backward selection mode of a step-wise regression to test the relation between DXA values of body mass and the values determined from the chemical analysis of body composition. Single and multivariate regression models were then constructed to predict the fat mass from DXA readings. We report the results of our statistical analysis in terms of their $R^{2}$ and $P$ values. For statistical analysis, we used SPSS (version 20).

\section{Results}

\section{DXA validation}

Six geckos were used for the validation portion of this study (Table 1). The values of fat mass as determined by DXA (raw data) were highly correlated to the chemically extracted fat mass values (Linear regression: $N=6, R^{2}=0.834, P=0.011$; Fig. 1). Removing the smallest, unsexed gecko improved the error from $54 \%$ to $8.5 \%$ (Linear regression: $N=5, R^{2}=0.995, P<0.001$; Fig. 1 ). We found a linear correlation $\left(R^{2}=0.995\right)$ and a lack of significant difference between fat content by chemical extraction and by DXA estimation (Paired t-test: $t 4=-0.03 ; P=0.998$ ).

Table 1. Sex, snout-vent length (SVL), wet body mass and fat mass chemical extraction of six Israeli fantoed geckos Ptyodactylus guttatus used to validate the application of dual-energy X-ray absorptiometry (DXA) to non-invasively calculated body fat indices in small lizards. 


\begin{tabular}{|lllll|}
\hline Sex & SVL $(\mathrm{mm})$ & Live Wet Mass $(\mathrm{g})$ & Fat Extraction $(\mathrm{g})$ & DXA Reading $(\mathrm{g})$ \\
\hline Male & 61.51 & 4.8 & 0.26 & 1.5 \\
\hline Male & 87.45 & 11 & 0.37 & 1.65 \\
\hline Female & 80.74 & 10.9 & 1.60 & 2.4 \\
\hline Female & 65.97 & 11.5 & 2.09 & 2.8 \\
\hline Female & 67.14 & 6.5 & 0.93 & 2 \\
\hline Unknown & 55.64 & 4.2 & 0.43 & 0.95 \\
\hline
\end{tabular}

\section{Accuracy of DXA for calculating mass}

To determine the accuracy of the DXA in calculating mass compared to actual weighed mass, we compared all lizards above $4.8 \mathrm{~g}$. The DEXA results were highly correlated to live wet mass (linear regression: $N=30, R^{2}=0.984, P<0.001$; Fig. 2) and chemically extracted fat mass: $N=5, R^{2}=0.995, P<0.001$.

\section{Models of fat percentage and mass}

A simple linear regression of calculated vs. predicted fat percentage was significant $(P=0.045)$ but the percentage of explained variation was low $\left(R^{2}=0.136\right)$. Therefore, we regressed a multivariate regression model, constructed with mass and calculated fat\% as predictors to predict the percentage from DXA: $N=30, R_{\text {adj. }}^{2}=0.875, P<0.001$ (Fig. 3). We excluded specimens lighter than $4.8 \mathrm{~g}$. Average total body wet mass was comprised of $11.9 \%$ body fat. Females possessed a larger percentage of their body mass as fat $13.2 \%$ compared to males, 9.8\%; however, this difference was not significant (Mann-Whitney Test $N_{\text {Males }}=10, N_{\text {Females }}=16, Z=-1.083, P_{\text {Two-tailed }}=0.279$ ).

\section{Comparisons of DXA to calculated $\mathrm{Cl}$}

We applied five different morphological condition indices that are commonly used on reptiles to the 30 geckos in the dataset in order to determine their accuracy. The indices tested were 1) residuals of the regression of SVL (mm) versus Mass (g); 2) width of tail base; 3) mass/SVL; 4) mass/SVL 2 ; 5 ) mass/SVL ${ }^{3}$.

All body indices were highly correlated with each other $(P<0.05)$. In the correlations between calibrated body fat $\%$ and body condition indices was largest for mass $/ \mathrm{SVL}$ index $\left(r_{\text {Mass } / \mathrm{SVL}}=0.83\right.$, and $P_{\mathrm{Two}}$ tailed $^{<0.001)}$. The correlation coefficient was highest for the Mass/SVL index > width of tail base > mass $/ \mathrm{SVL}^{2}>\mathrm{OLS}>\mathrm{Mass} / \mathrm{SVL}^{3}$ (Pearson Correlation values were $0.83,0.76,0.70,0.652$, and 0.40 ). When correlating separately by sex, the width of tail base was best in males $\left(r_{\text {Tail base width }}=0.961, P<0.001\right)$ and not significant for females $\left(r_{\text {Tail base width }}=0.206, P<0.480\right)$.

\section{Discussion}


Non-invasive and non-destructive techniques to determine the condition of individual animals are preferential to destructive methods requiring euthanasia, especially for rare and endangered species or in cases of strict laws concerning wildlife protection or animals' rights laws. These sorts of longitudinal measures allow for greater understanding of life-history traits and behaviour. A variety of non-invasive techniques have been trialed, at varying levels of success, to measure fat stores in reptiles, but none have been tested and verified on small free-ranging lizards. This study was aimed to determine whether dualenergy X-ray absorptiometry (DXA), a non-destructive method that accurately measures fat mass in humans and other mammals, could be used to determine the fat mass in the small, common Israeli fantoed gecko. We found that the lowest value for body mass calculation by the DXA machine and that was still accurate was $4.8 \mathrm{~g}$. Thus, when we exclude the smallest gecko $(4.2 \mathrm{~g})$ we found that DXA and chemical extraction of fat mass were significantly correlated. Regression equations using DXA values were able to predict the fat mass and total gravimetric body mass accurately with an average error of $8.55 \%$ and $3.5 \%$ respectively. Using the predicted DXA values, we were able to test common body condition indices against both actual and predicted DXA values and show that mass/SVL was the most accurate method for estimating the condition index of these small lizards. Measuring the tail base width was not correlated with females body percentage; however for males, it was slightly more accurate than mass/SVL ( $R=0.961, P<0.001 ; R=0.874, P=0.001$, respectively). Females may store fat mostly in the abdomen for reproductive energy. This may explain why the tail base width was not correlated with fat percentage in females, while it was the best indicator for fat percentage in males.

\section{Non-destructive methods for $\mathrm{Cl}$}

Previous work on reptile body condition indices and non-destructive sampling have been notoriously inaccurate. Secor and Nagy (2003) found that two indices for body condition (mass/SVL and mass/SVL ${ }^{2}$ ) predict the fat mass of diamondback water snakes (Nerodia rhombifer) with significantly different values from the DXA and chemical analysis results (mean error ranging from $20 \%$ to $41 \%$ ). Weatherhead \& Brown (1996) found another index method (based on logged mass residuals) to be relatively unreliable in predicting fat mass of northern water snakes ( $N$. sipedon). Other methods for the estimation of fat percentage (e.g., Bioelectrical Impedance Analysis) have been fairly successful in predicting body condition, but again they lack accuracy (Secor \& Nagy, 2003; Helminsky \& DeNardo, 2000). Total body electrical conductivity (TOBEC) is an additional technique and is relatively simple, however, it is sensitive to body size, shape, temperature and hydration state, distribution of lean tissue, movement and position of the animal. For the eastern fence lizard Sceloporus undulates, TOBEC estimates of fat free dry mass and fat mass were able to predict the actual amounts present with an average error of $5.8 \%$ and $30.3 \%$, respectively. Of all the non-invasive methods used to quantify body composition, the most accurate is DXA. The mean error percentage for fat mass we calculated for using DXA was $8.55 \%$ when the animal body mass was heavier than $4.8 \mathrm{~g}$. This percentage designated the difference between the fat mass predicted by the model and the fat mass that was extracted chemically. The mean error of the wet body mass was even lower, at 3.5\%. Thus, the body index method we useddirect measuring of body fat\% by DXA was proved to be most reliable and highly correlated to the results, extracted chemically. 


\section{Practical use of DXA and $\mathrm{Cl}$}

We found that DXA was a reliable rapid and accurate means to predict fat mass and body mass in live small lizards. It enables a researcher to accurately track seasonal and ontogenetic changes in an individual and to correlate these changes to fitness traits. The machine and software were easy to use, and such machines are widely available due to DXA use in human medicine. As in all such techniques, a validation study is required to generate the predictive models, which requires the destructive sampling of individuals under study. This is a drawback for studies on rare species. Another drawback is the necessity that subjects remain absolutely still, which requires anesthesia. In a pilot trial, we attempted to place the lizards in the freezer prior to the trial to prevent them from moving during the scanning phase, but this proved unreliable and had to be substituted with an anesthesia which can prove fatal in overdose. When comparing five common traditional Cl's, we found that mass/SVL was the index with the highest correlation coefficient to the DXA estimates. We conclude that when DXA is not available, mass/SVL is the most reliable alternative index and should be used unless actual fat mass is required. In situations where more accuracy is needed, DXA is a suitable method for small lizards. An interesting question raised here, is the insignificant correlation between females tail base width and fat percentage, while in males it was the best predictor $(r=0.961)$. This result should be explored in other species of lizards in order to understand if this result is a general basic physiological difference between the sexes.

\section{Abreviations}

Cl: condition index

DXA: dual-energy X-ray absorptiometry

SVL: snout-vent length

TOBEC: Total body electrical conductivity

\section{Declarations}

\section{Ethics approval and consent to participate}

This work was done under the ethical regulations of Ben Gurion University in the years 2003-2004, under state laws and regulations complying with a special permit from the Israeli Nature and National Parks Protection Authority (permit 2004/38393).

\section{Consent for publication}

Not applicable.

\section{Availability of data and materials}


Data are freely available from the paper and will be provided in a supplementary file.

\section{Competing interests}

The authors declare that they have no competing interests

\section{Funding}

No specific funding for this work was received.

\section{Authors' contributions}

The work was mainly conceived and designed by AB and GS. Experimental data were collected and analyzed by GS. The manuscript was mainly written by GS and MW, and revised by AB. All the authors contributed to the writing, reading and approval of the final manuscript.

\section{Acknowledgements}

We thank Berry Pinshow who made this study possible, Michal S. Wojciechowski for almost all the X-ray scans. We thank Yehudah L. Werner, Herve Seligman, Aviad Eilam, Marshall Mccue and Francisco Sánchez for advice and help and Carmi Korine for his technical support and patience. We thank Noga Kronfeld-Schor for technical advice and guidance with the fat calibration. Last but not least, we thank Gilad Grader Sageev for his help in the field work and curiosity that knew no boundary. May he rest in peace.

\section{References}

1. Angilletta MJ. Jr. Estimating body composition of lizards from total body electrical conductivity and total body water. Copeia. 1999;3:587-95.

2. Atkinson SN, Ramsay MA. The effects of prolonged fasting of the body composition and reproductive success of female polar bears (Ursus maritimus). Funct Ecol. 1995;9:559-67.

3. Blanc S, Colman R, Kemnitz J, Weindruch R, Baum S, Ramsey J, Schoeller D. Assessment of nutritional status in rhesus monkeys: comparison of dual-energy X-ray absorptiometry and stable isotope dilution. J Med Primatol. 2005;34:130-8.

4. Cozzi $B$, Panin $M$, Butti $C$, Podestà $M$, Zotti $A$. Bone density distribution patterns in the rostrum of delphinids and beaked whales: evidence of family-specific evolutive traits. Anat Rec. 2010;293:23542.

5. Dobush GR, Ankney CD, Krementz DG. The effect of apparatus, extraction time, and solvent type on lipid extractions of snow geese. Can J Zool. 1985;63:1917-20.

6. Falk BG, Snow RW, Reed RN. A validation of 11 body-condition indices in a giant snake species that exhibits positive allometry. PloS One. 2017;12:e0180791. 
7. Frankenberg E. Pupillary response and visual behavior with relation to activity times in geckos of various species (PhD Dissertation). The Hebrew University, Israel. 1978.

8. Gamble T, Bauer AM, Greenbaum E, Jackman TR. Out of the blue: a novel, trans-Atlantic clade of geckos (Gekkota, Squamata). Zool Scr. 2008;37:355-66.

9. Gutman R, Choshniak I, Kronfeld-Schor N. Defending body mass during food restriction in Acomys russatus: a desert rodent that does not store food. Am J Physiol Regul Intergr Comp Physiol. 2006;290:R881-91.

10. Green AJ. Mass/length residuals: measures of body condition or generators of spurious. results? Ecology. 2001;82:1473-83.

11. Hadley NF. The Adaptive Role of Lipids in Biological Systems. New York: John Wiley and Sons; 1985.

12. Henen BT. Gas dilution methods: elimination and absorption of lipid-soluble gases. In JR Speakman, editor Body Composition Analysis of Animals: A Handbook of Non-Destructive Methods. Cambridge University Press 2001;99-126.

13. Hwang YT, Larivière S, Messier F. Evaluating body condition of striped skunks using non-invasive morphometric indices and bioelectrical impedance analysis. Wildl Soc Bull. 2005;33:195-203.

14. Johnson MS, Watts RJ, Hammer HS, Nagy TR, Watts SA. Validation of dual-energy X-ray absorptiometry to predict body composition of channel catfish, Ictalurus punctatus. J World Aquacult Soc. 2017;48:122-31.

15. Johnston G, Bouskila A. Sexual dimorphism and ecology of the gecko, Ptyodactylus guttatus. J Herpetol. 2007;41:506-13.

16. Korine C, Daniel S, van Tets IG, Yosef R, Pinshow B. Measuring fat mass in small birds by dual-energy X-ray absorptiometry. Physiol Biochem Zool. 2004;77:522-9.

17. Meylan S, Belliure J, Clobert J, de Fraipont M. Stress and body condition as prenatal and postnatal determinants of dispersal in the common lizard (Lacerta vivipara). Horm Behav. 2002;42:319-26.

18. Milenkaya O, Catlin DH, Legge S, Walters JR. Body condition indices predict reproductive success but not survival in a sedentary, tropical bird. PLoS One. 2015;10:e0136582.

19. Nagy TR. The use of dual-energy X-ray absorptiometry for the measurement of body composition. In JR Speakman, editor Body Composition Analysis of Animals: A Handbook of Non-Destructive Methods. Cambridge University Press 2001;211-229.

20. Nagy TR, Clair AL. Precision and accuracy of dual-energy X-ray absorptiometry for determining in vivo body composition of mice. Obes Res. 2000;8:392-8.

21. Peig J, Green AJ. New perspectives for estimating body condition from mass/length data: the scaled mass index as an alternative method. Oikos. 2009;118:1883-91.

22. Poisbleau M, Fritz H, Valeix M, Perroi PY, Dalloyau S, Lambrechts MM. Social dominance correlates and family status in wintering dark-bellied brent geese, Branta bernicla bernicla. Anim Behav. 2006;71:1351-8. 
23. Prestrud P, Pond CM. Fat indices of arctic foxes Alopex lagopus in Svalbard. Wildlife Biol. 2003;9:193-7.

24. Riley JL, Baxter-Gilbert JH, Guglielmo CG, Litzgus JD. Scanning snakes to measure condition: a validation of quantitative magnetic resonance. J Herpetol. 2016;50:627-32.

25. Rossi S, Sánchez-Sarmiento AM, dos Santos RG, Zamana RR, Prioste FES, Gattamorta MA, Ochoa PFC, Grisi-Filho JHH, Matushima ER. Monitoring green sea turtles in Brazilian feeding areas: relating body condition index to fibropapillomatosis prevalence. J Mar Biol Assoc U K. 2019;99:1879-87.

26. Scott I, Selman C, Mitchell P. The use of total body electrical conductivity (TOBEC) to determine body composition. In JR Speakman, editor Body Composition Analysis of Animals: A Handbook of NonDestructive Methods. Cambridge University Press 2001;127-160.

27. Secor SM, Nagy TR. Non-invasive measure of body composition of snakes using dual-energy x-ray absorptiometry. Comp Biochem Physiol A: Mol Integr Physiol. 2003;136:379-89.

28. Servello FA, Hellgren EC, McWilliams SR. Techniques for wildlife nutritional ecology. In CE Braun, editor. Techniques for Wildlife Investigations and Management, 6th Edition. The Wildlife Society, Bethesda, Maryland. 2005;554-590.

29. Sion G. Foraging strategy and social hierarchy are state dependent in the gecko Ptyodactylus guttatus (M.Sc.Thesis). Ben-Gurion University of the Negev, Israel. 2006.

30. Sion G. Inter-relations among behavior, physiology, morphology and directional asymmetry in the gecko Ptyodactylus guttatus (PhD Dissertation). The Hebrew University, Israel. 2015.

31. Sion G. Foot-preference underlies bite-scar asymmetry in the gecko Ptyodactylus guttatus. Laterality. 2018;23:129-51.

32. Speakman JR. Body Composition Analysis of Animals: A Handbook of Non-Destructive Methods. Cambridge: Cambridge University Press; 2001.

33. Stephenson TR, Bleich VC, Pierce BM, Mulcahy GP. Validation of mule deer body composition using in vivo and post-mortem indices of nutritional condition. Wildl Soc Bull. 2002;30:557-64.

34. Stevenson RD, Woods Jr. WA. Condition indices for conservation: new uses for evolving tools. Integ Comp Biol. 2006;46:1169-90.

35. Taillon J, Côté SD. Social rank and winter forage quality affect aggressiveness in white-tailed deer fawns. Anim Behav. 2007;74:265-75.

36. Thornton A. Early body condition, time budgets and the acquisition of foraging skills in meerkats. Anim Behav. 2008;75:951-62.

37. Vervust B, Lailvaux SP, Grbac I, Van Damme R. Do morphological condition indices predict locomotor performance in the lizard Podarcis sicula? Acta Oecol. 2008;34:244-51.

38. Wells CP, Wilson JA, Kelt DA, Van Vuren DH. Body mass as an estimate of female body condition in a hibernating small mammal. Can Field-Nat. 2019;133:34-42.

39. Wirsing AJ, Steury TD, Murray DL. Noninvasive estimation of body composition in small mammals: a comparison of conductive and morphometric techniques. Physiol Biochem Zool. 2002;75:489-97. 
40. Werner D. Beobachtungen an Ptyodactylus hasselquistii guttatus Geckonidae). Naturf. 1972;82:5487.

41. Werner YL, Sivan N. Systematics and zoogeography of Ptyodactylus (Reptilia: Sauria: Gekkonidae) in the Levant: 2, Taxonomy, with a review of ecology and zoogeography. Rev Esp Herp. 1994;8:105-22.

42. Werner YL. Ueber die israilischen Geckos der Gattung Ptyodactylus und ihre Biologie. Salamandra. $1965 ; 1: 15-25$.

43. Werner YL. Ecology of eggs and laying sites of Ptyodactylus geckos. In Z Rocek, editor. Studies in Herpetology: Proceedings of the European Herpetological Meeting (Czech Republic). Charles University Press. 441-444.

44. Xuefeng $X$, Yilian W. Annual variation of water content and energy value of the major energy reserves in adult lizards (Eremias brenchleyi). Acta Zool Sin. 2003;49:191-7.

45. Zotti A, Selleri P, Carnier P, Morgante M, Bernardini D. Relationship between metabolic bone disease and bone mineral density measured by dual-energy $\mathrm{X}$-ray absorptiometry in the green iguana (Iguana iguana). Vet Radiol Ultrasound. 2004;45:10-6.

46. Zlotkin E, Milman T, Sion G, Werner YL. Predatory behavior of the gekkonid lizards, Ptyodactylus spp., toward the scorpion Leiurus quinquestriatus hebraeus, and their tolerance of its venom. J Nat Hist. 2003;37:641-6.

\section{Figures}




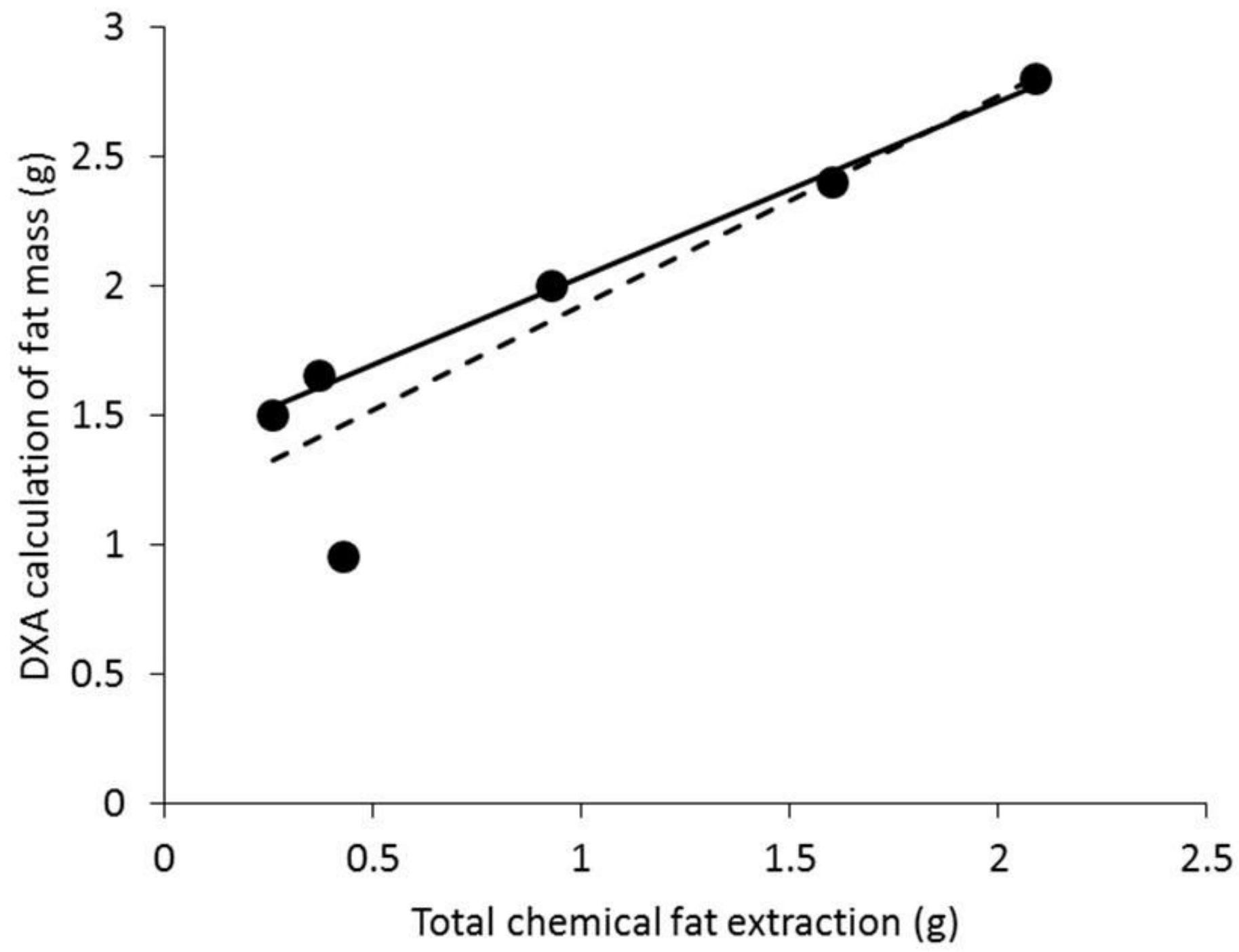

Figure 1

Correlation between actual total fat as determined by chemical extraction and DXA calculation of fat mass as determined by DXA (dashed line including the smallest lizard: R2 $=0.834$; solid line excluding the smallest lizard $(R 2=0.995)$. 


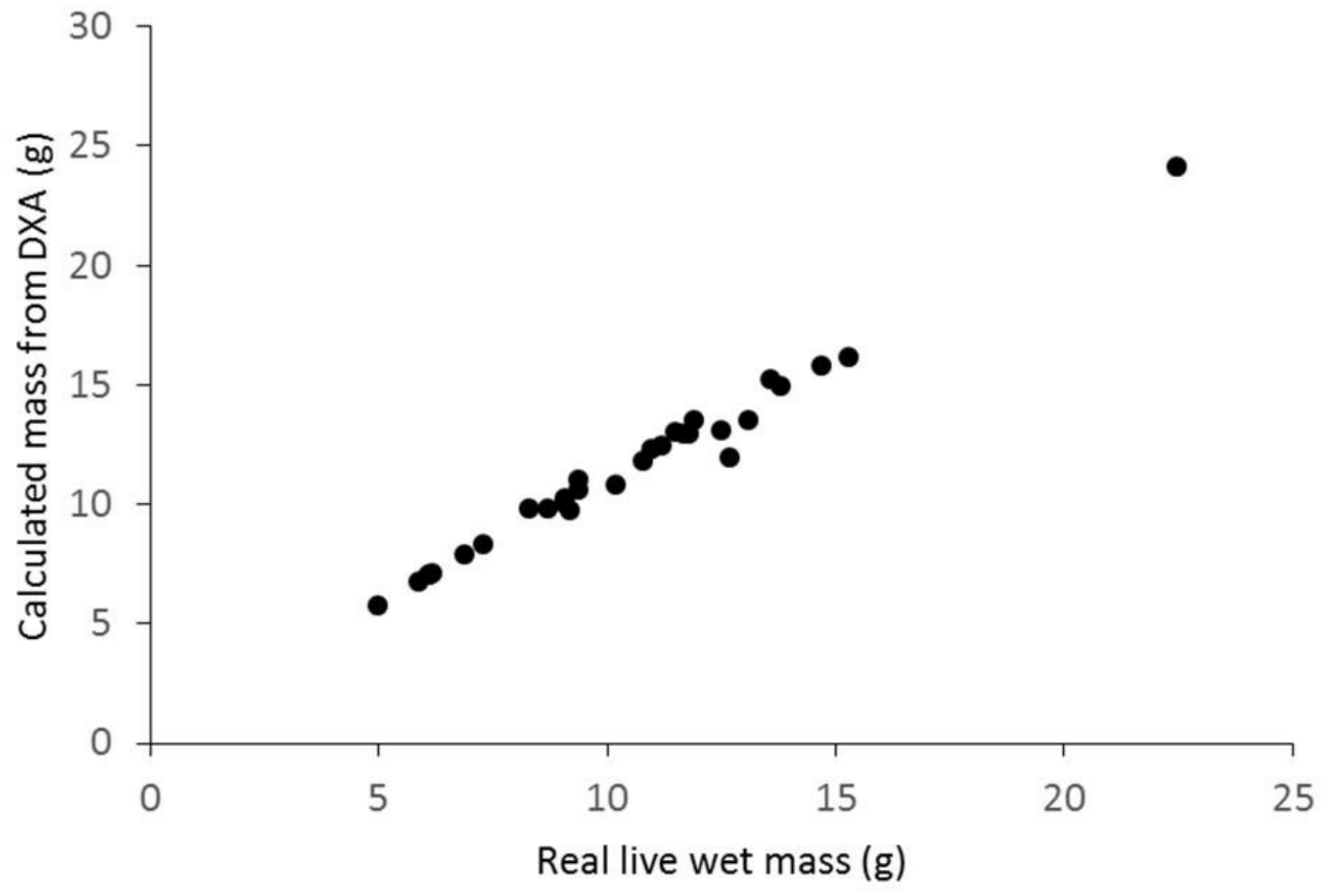

Figure 2

The values of body mass taken from the machine as raw data (as is) vs. body mass values measured by scales. Linear regression: $\mathrm{N}=30, \mathrm{R} 2=0.984, \mathrm{P}<0.001$. 


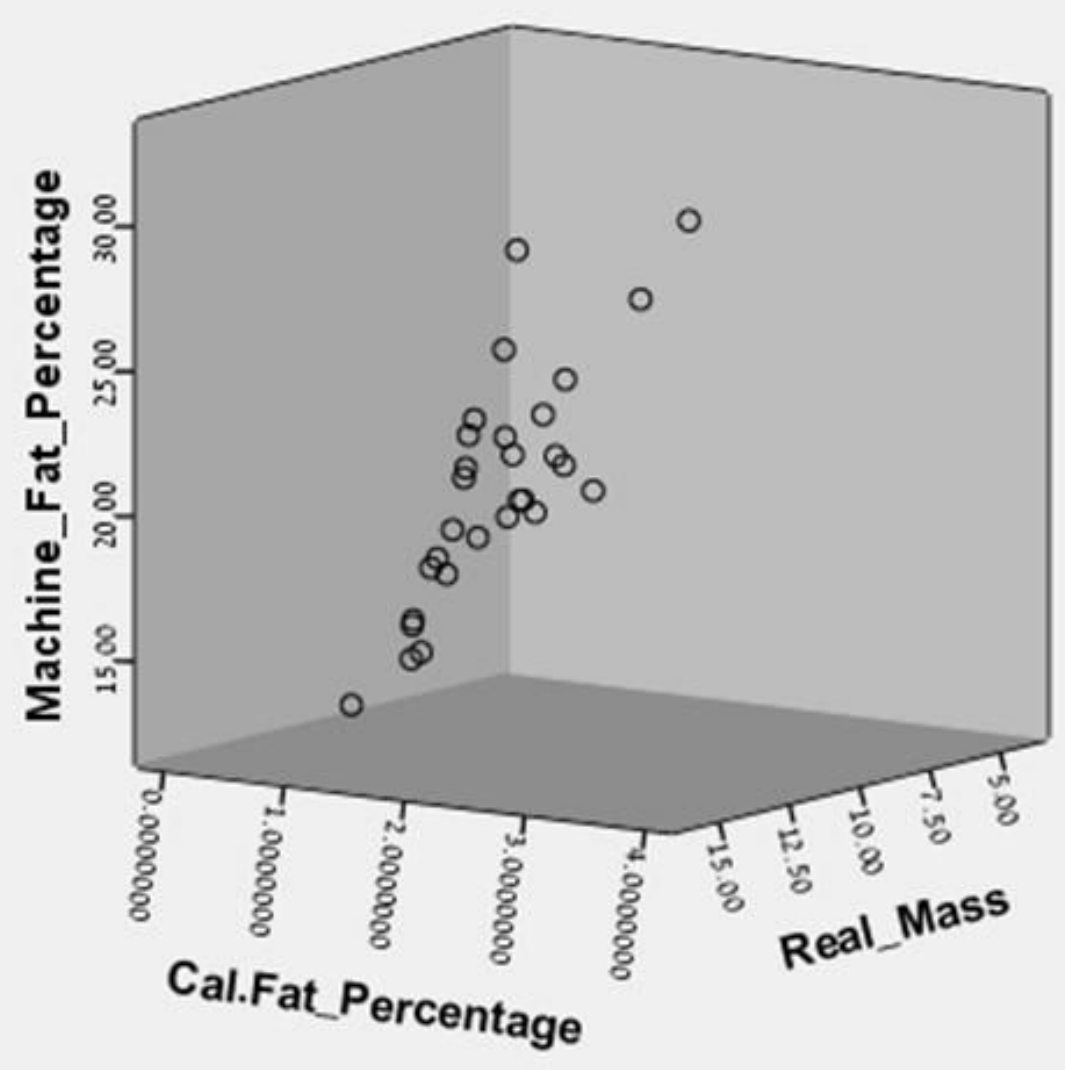

Figure 3

A multivariate model of DXA calculated fat percentage (Machine_Fat_Percentage), calculated fat percentage (Cal.Fat_Percentage) and actual measured live wet mass (Real_Mass). 